\title{
In Memoriam Michael D. Goldman, M.D.
}

Sadly, during completion of this special issue, Michael D. Goldman, M.D., passed away unexpectedly. Dr. Goldman was a highly accomplished respiratory physiologist who had closely collaborated in the past decade with psychophysiologists to further our understanding of behavioral and experiential factors in respiration. Starting his career in the 1960s at the Harvard School of Public Health, he worked with Jere Mead, the father of respiratory mechanics, and with him, was among the pioneers in the development of mechanical lung function measurement techniques, such as the forced oscillation method and respiratory inductance plethysmography. He published an influential body of research on the mechanical work of breathing and respiratory muscle function and served on editorial and national review boards of physiology and sports medicine. Later in his career, he worked on the further development and clinical application of impulse oscillometry for diagnosis of respiratory disease. Before the abrupt end of his productive life, he was actively involved in several national and international collaborations, which included the modeling of respiratory mechanics, the diagnostic use of frequency-dependence of airflow resistance, the diagnosis of lung disease by the inert gas washout technique, and the influence of stress and emotion on airway mechanics. His efforts in bridging the disciplines of medicine, engineering, and psychology were tireless and infectious in their enthusiasm. Always the brilliant colleague, patient adviser, and humble scientist, he will be irreplaceable for the community of respiratory psychophysiologists who came to enjoy his unique creativity, impressive expertise, and generosity in sharing his knowledge.

Thomas Ritz* Omer Van den Bergh Southern Methodist University, Department of Psychology, P.O. Box 750442, Dallas, TX 75275-0442,

United States

* Corresponding author. Tel.: +1 214768 3724; fax: +1 2147683910 . E-mail address:tritz@smu.edu (T. Ritz)

Available online 8 April 2010 